\title{
TEMPORAL AND SPATIAL DISTRIBUTIONS OF NUTRIENTS AND POLLUTION RISK ASSESSMENT OF TAXODIUM 'ZHONGSHANSHAN' WETLAND OF DIANCHI LAKESIDE, SOUTHWEST OF CHINA
}

\author{
LING, Z. ${ }^{1,2}-$ SHI, Z. $.^{*}-$ XU, S. ${ }^{3}-$ DONG, M. ${ }^{2}$ \\ ${ }^{1}$ College of Tourism and Geographic Sciences, Yunnan Normal University, 650500 Yunnan, \\ China \\ ${ }^{2}$ Kunming University, Kunming, 650214 Yunnan, China \\ ${ }^{3}$ Kunming Dianchi Lake Pollution Prevention and Control Cooperative Research Center, \\ 650214 Yunnan, China \\ *Corresponding author \\ e-mail: shizhengtao@163.com
}

(Received $5^{\text {th }}$ Aug 2019; accepted $25^{\text {th }}$ Nov 2019)

\begin{abstract}
The Taxodium 'zhongshanshan' is one of the main wetland plants of lakeside of a plateau Dianchi Lake, in Southwest of China. The sediments and overlying water samples of the $T$. 'zhongshanshan' wetland were collected. The temporal and spatial distributions of the total nitrogen $(\mathrm{TN})$, total phosphorus (TP) and total organic matter (OM) were analyzed by principal component analysis (PCA) and correlation coefficient method. The pollution risk assessment of $T$. 'zhongshanshan' in Wetland. The results showed that: (1) There were differences in the temporal and spatial distributions of nutrients in the dynamic groundwater of $T$. 'zhongshanshan' wetland. In overlying water, the TP, TN and SS were higher in rainy season than in dry season. The removal rates of TN and TP were higher in dry season than in rainy season. The pollutant in the upstream were higher than the downstream. (2) The sediment pollution sources of nitrogen and phosphorus in wetland were also different in the rainy and dry seasons. The TP in sediment were higher in rainy season than in dry season. (3) The comprehensive pollution index was combined with the organic index to provide an evaluation method. The TN and TP content reached a heavy pollution level and the organic contaminants were at a medium level.

Keywords: Taxodium 'zhongshanshan' wetland, nutrients distribution characteristics, pollution index, organic matter index, organic nitrogen index
\end{abstract}

\section{Introduction}

Dianchi Lake Basin is a region with the highest level of urbanization in Yunnan Province, Southwest of China. The deterioration of the water environment and eutrophication in Dianchi Lake seriously restrict the sustainable development of the region (Xue and $\mathrm{Lu}, 2015$; $\mathrm{Li}$ et al., 2015). It is the key watershed of "Three rivers and three lakes" management project in China. People have paid close attention to the temporal and spatial distribution characteristics and environmental significance of nutrient elements, assessment pollution risk of nutrients in lakeside wetlands of Dianchi.

The Lakeside wetlands could intercept pollution into lakes, restore the function of terrestrial and aquatic ecosystems and maintain water quality of lakes and improve the ecological landscape of lakes, which play an important role as barrier for eutrophic lakes (Wondie, 2018; Reeves et al., 2018). Also the lakeside wetlands control the lake eutrophication. To restore the ecosystem of eutrophic lakes, a 54,000 ha of lakeside ecological rehabilitation zone and 800,000 plants of T. 'zhongshanshan' ecoregion have 
been constructed in the lakeside wetland of Dianchi Lake. There are many studies have shown that the $T$. 'zhongshanshan' have a good capacity to purify different concentration of eutrophic water (Hua et al., 2013; Han et al., 2015) and reduce the concentration of nitrogen and phosphorus in the ecological rehabilitation zone of wetland (Mayo et al., 2018; Oldenborg and Steinman, 2018).

Although, there are many related research reports in the Take Griffin Lake Wetland, Louisiana Rainy Land, Caohai Typical Plateau Wetland and Typical Lakes of QinghaiTibet Plateau (Zhang et al., 2013; Marton et al., 2014; Fulton et al., 2015). These results indicated that the spatial distribution and release potential of pollutant indicator have the obvious differences in lakeside wetlands. Temporal and spatial of nutrients has important impact on wetland ecosystem restoration and further affected the restoration of eutrophic lakes. However, combined nutrient distribution and assessment risk of pollutant has rarely been reported, especially in the lakeside wetland of plateau eutrophic lake.

The Laoyuhe River is one of the 35 main rivers input Dianchi Lake, which is typical contaminated non-point source pollution. During 2002 and 2004, the water quality of the Laoyuhe River was worse than Grade V due to lack of protection and management, and the main pollution index were the TN and TP. According to Laoyuhe River pollutants characteristics, a $20 \mathrm{hm}^{2}$ of the $T$. 'zhongshanshan' ecological restoration area was constructed near the estuary of Laoyuhe River. The removal rate of TP and TN respectively reached $37.1 \%$ and $67.5 \%$ in ecological restoration wetland of the Laoyuhe River. The annual COD reduction of the pollution load was $473.2 \mathrm{t}$, TP $1.703 \mathrm{t}$, TN $79.1 \mathrm{t}$ and SS $483.7 \mathrm{t}$ by the ecological restoration wetland of the Laoyuhe River (Ma et al., 2007). Laoyuhe River wetland is the largest, last biological barrier in the lakeside of Dianchi Lake where $T$. 'zhongshanshan' is the typical and main trees. It plays an important roles in reduce pollution from the agricultural non-point source.

This research is aim to systematically analyze the temporal and spatial distributions characteristics and ecological effects of sediments in the ecological restoration area of the $T$. 'zhongshanshan' in the lakeside wetland. It is contained the temporal and spatial distribution characteristics of TP, TN and OM in sedimentsand the interaction between sedimentoverlying water and the evaluation of pollution level in T. 'zhongshanshan' wetland.

\section{Materials and methods}

Study area and Sampling sites as shown in Figure 1. The Laoyuhe River wetlands about $53.34 \mathrm{hm}^{2}\left(108^{\circ} 48^{\prime} 46^{\prime \prime}-108^{\circ} 52^{\prime} 09^{\prime \prime} \mathrm{E}, 22^{\circ} 56^{\prime} 28^{\prime \prime}-23^{\circ} 0{ }^{\prime} 49^{\prime \prime} \mathrm{N}\right)$ has formed a wetland ecosystem in the River-Lake interaction area. In addition, plenty of $T$. 'zhongshanshan' has been planted in that wetland area which plays an important role in purifying water quality, intercepting pollutants, controlling soil loss and improving lakeside landscape.

Moreover, the study area forms the unique regional precipitation unit in the dry season during October to April and rainy seasons during May to September in the YunnanGuizhou Plateau. So that the hydrological processes (Weyer et al., 2018), wetland vegetation suitability (Pan et al., 2012), nutrient transport and transformation in sediments (Naranjo et al., 2019) of the Laoyuhe River are mainly affected by dry and rainy seasons.

\section{Sediment and water sample treatment and statistical analysis}

In this study, 27 sample sites (A1-A9, B1-B9, C1-C9) as marked in Figure 1 were located in the central of $T$. 'zhongshanshan' ecological restoration area in Laoyuhe River wetland near Dianchi Lake. A1-A9 were located at downstream, B1-B9 were 
located at midstream, C1-C9 were located at upstream. Surface sediment $(0-10 \mathrm{~cm})$ and overlying water are collected by using a home-made core Plexiglas sampler (Zhang, 2014) in May 27, 2018 (rainy season) and November 27, 2018 (dry season). The samples collected from each site consisted of three parallel samples. Following collection, the sediment and overlying samples were sealed in plastic bags and bottles were transported to the laboratory in cooled boxes at $4{ }^{\circ} \mathrm{C}$. Each sediment sample was freeze-dried, ground, and passed through a $0.15-\mathrm{mm}$ sieve.
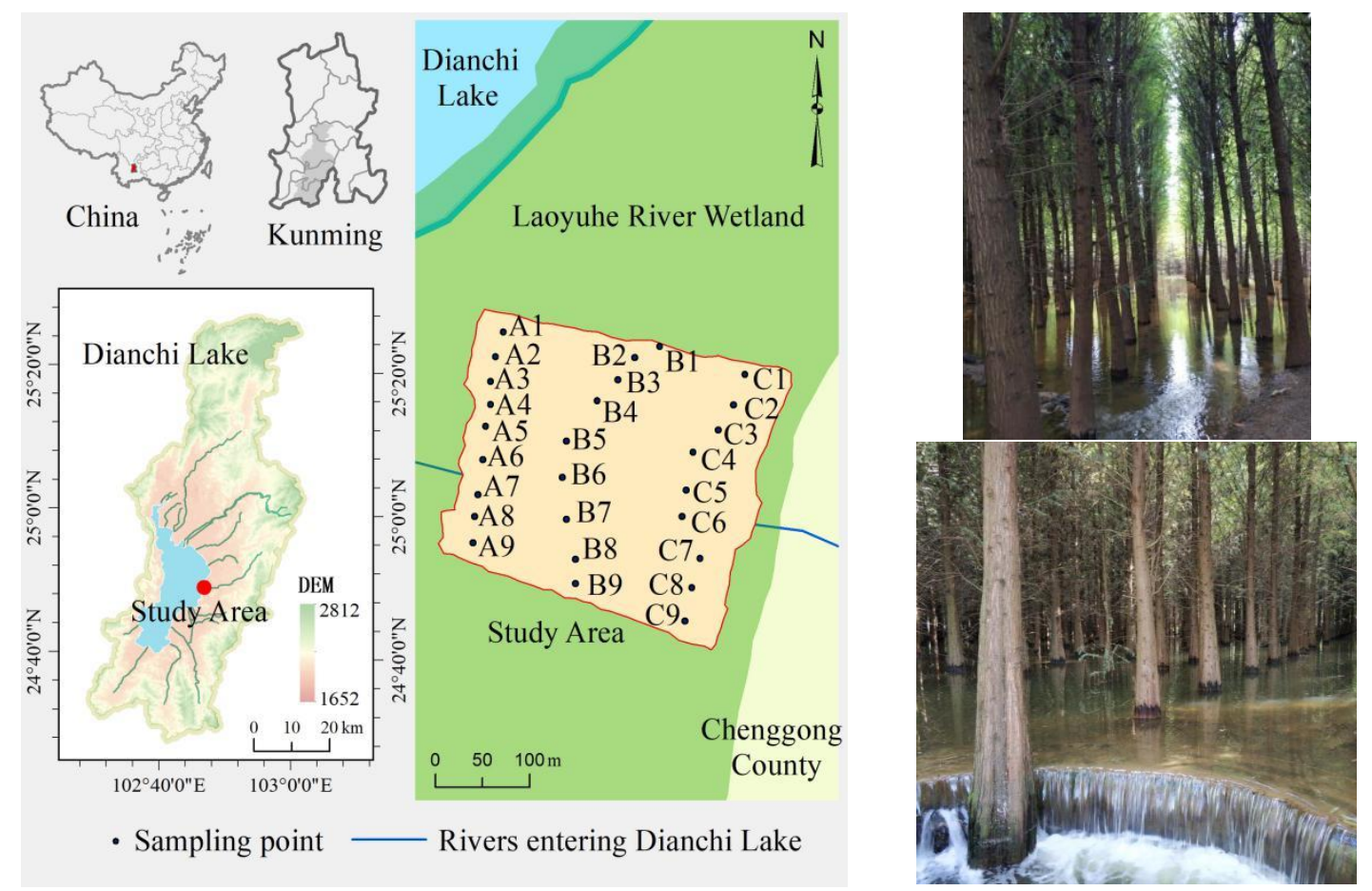

Figure 1. Locations of sampling sites and pictures of Laoyuhe River wetlands around Dianchi

To measure TP in the sediment samples, TP in acid-digested extract was determined by the ascorbic acid method using a Shimadzu UV-3600 spectrophotometer. TN was determined using an elemental analyzer (CE-440, Exeter Analytical, Inc., North Chelmsford, MA, USA). To measure OM which were analyzed by potassium dichromate oxidation-external heating (Zhang et al., 2014).

Suspended Solids (SS), Total nitrogen (TN) and Total phosphorus (TP) were tested and analyzed in overlying water. The parameters of water samples were determined according to the Monitoring Method for Water and Wastewater (4th Edition). SS was filtered by centrifuge and filter paper. National Standards HJ 636- 2012 and GB 11893-89 illustrated that TN was determined by alkaline potassium persulfate oxidation-ultraviolet spectrophotometry and that TP was determined by ammonium molybdate spectrophotometry. The average of three parallel samples for each index is tested for reduce error, and the laboratory error is controlled within 5\%. The data were analyzed by SPSS20.0 and Excel 2013 software for the principal components of TN, TP, OM in sediments and SS, TN and TP in the overlying water of each sampling point in the research area. Then the correlation between different index also be studied. 
The nutrient element distribution diagram of the study area was drawn by GraphPad.Prism5 software in order to compare and analyze the distribution characteristics of different nutrient elements in the sediment-overlying water in the dry and rainy season.

\section{Pollution assessment method of T. 'zhongshanshan' ecoregion}

\section{Comprehensive pollution index evaluation}

The assessment criteria of TN and TP $(0.55$ and $0.60 \mathrm{~g} / \mathrm{kg})$ used in this paper. They are consistent with the contents of TN and TP in sediments that can cause the lowest level of ecological risk effects issued by the Department of Environment and Energy, Ontario, Canada (1992) (Li et al., 2016). The formula for calculating single pollution index is (Kapelewska et al., 2018):

$$
\begin{gathered}
S_{i}=\frac{c_{i}}{c_{s}} \\
F F=\frac{\sqrt{F^{2}+F_{\max }^{2}}}{\sqrt{2}}
\end{gathered}
$$

where $S_{i}$ is a single evaluation index or standard index, $S_{i}>1$ indicates that the content exceeds the evaluation standard value; $C_{i}$ is the measured value of evaluation factor $i$ $(\mathrm{g} / \mathrm{kg}) ; C_{s}$ is the evaluation standard value of evaluation factor $i(\mathrm{~g} / \mathrm{kg})$. The $C_{s}$ of TN is $0.55 \mathrm{~g} / \mathrm{kg}$, the $C_{s}$ of TP is $0.60 \mathrm{~g} / \mathrm{kg} ; F F$ is the comprehensive pollution index; $F$ is the average value of n pollutant pollution indices (average of $S T N$ and $S T P$ ); $F_{\max }$ is the maximum single pollution index (maximum of $S T N$ and $S T P$ ). The comprehensive pollution for the surface sediments of Laoyuhe wetland shown in Table 1.

Table 1. Classification of comprehensive pollution degree of surface sediments in Laoyuhe River wetland

\begin{tabular}{c|c|c|c|c}
\hline Grade & STN & STP & FF & Pollution Level \\
\hline 1 & $\mathrm{STN}<1.0$ & $\mathrm{STP}<0.5$ & $\mathrm{FF}<1.0$ & Non-pollution \\
2 & $1.0 \leqq \mathrm{STN}<1.5$ & $0.5 \leqq \mathrm{STP}<1.0$ & $1.0 \leqq \mathrm{FF}<1.5$ & Mild pollution \\
3 & $1.5 \leqq \mathrm{STN}<2.0$ & $1.0 \leqq \mathrm{STP}<1.5$ & $1.5 \leqq \mathrm{FF}<2.0$ & Moderate pollution \\
4 & $\mathrm{STN}>2.0$ & $\mathrm{STP}>1.5$ & $\mathrm{FF}>2.0$ & Heavy pollution \\
\hline
\end{tabular}

\section{Organic pollution index evaluation}

The sediment pollution in T. 'zhongshanshan' wetland of Dianchi Lakeside was further evaluated by organic pollution index method for improve the evaluation results (Zhang et al., 2015; Yang et al., 2017). It is output of comprehensive information (Zhu et al., 2019) then it has advantages over the comprehensive pollution index evaluation.

According to Equations 3-5 and Table 2, the evaluation results of organic pollution of surface sediments in T. 'zhongshanshan' ecoregion around Dianchi Lake are shown in Table 4.

$$
10=O C(\%) \times O N(\%)
$$




$$
\begin{aligned}
& O N=T N(\%) \times 0.95 \\
& O C=O M(\%) / 1.724
\end{aligned}
$$

where $O C$ is organic carbon.

Table2. Evaluation criteria of organic index of surface sediments in Laoyuhe wetland

\begin{tabular}{c|c|c|c|c}
\hline Project & OI $<\mathbf{0 . 0 5}$ & $\mathbf{0 . 0 5} \leqq \mathbf{O I}<\mathbf{0 . 2 0}$ & $\mathbf{0 . 2 0} \leqq \mathbf{O I}<\mathbf{0 . 5}$ & OI $\geqq \mathbf{0 . 5}$ \\
\hline Level & Non-pollution & Mild pollution & Moderate pollution & Heavy pollution \\
Type & I & II & III & IV \\
\hline
\end{tabular}

\section{Results and analysis}

\section{Spatial distribution characteristics of nutrients in the ecological restoration area of} the T. 'zhongshanshan'

The Distribution characteristics of TN, TP and SS of the overlying water is shown in Figure 2 and TN, TP and OM contents in surface sediments of Laoyuhe River wetland during dry and rainy seasons is shown in Figure 3.

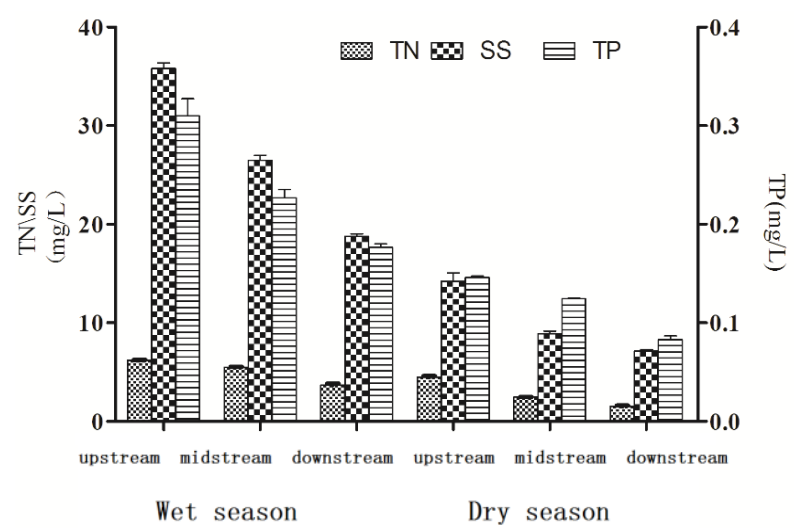

Figure 2. Distribution characteristics of TN, TP and SS of the overlying water in the ecological restoration area

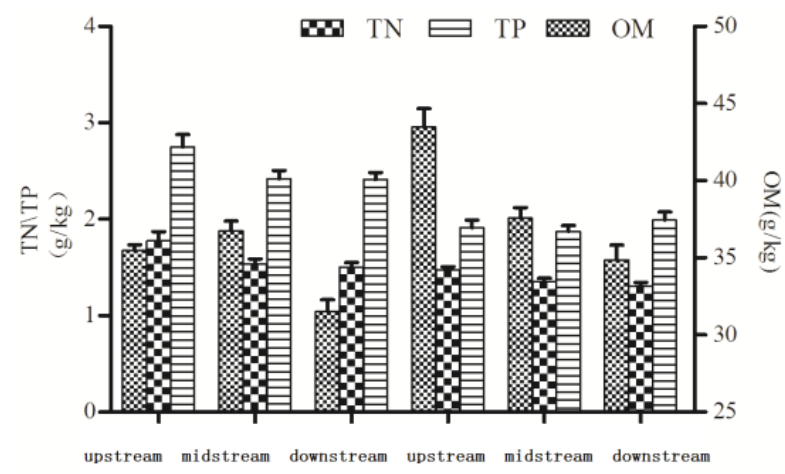

Wet season Dry season

Figure 3. Distribution characteristics of TN, TP and OM contents in surface sediments of Laoyuhe river wetland during dry and rainy seasons 
In the research area overlying water, the average values of TN was $5.13 \mathrm{mg} / \mathrm{L}$ and TP was $0.24 \mathrm{mg} / \mathrm{L}$ in rainy season, while $\mathrm{TN}$ is $2.83 \mathrm{mg} / \mathrm{L}$ and $\mathrm{TP}$ is $0.12 \mathrm{mg} / \mathrm{L}$ in dry season. The TN and TP in rainy season were nearly twice higher than in dry season.

All of TN, TP and SS decreases when the water flow through the ecological restoration area. The TN removal rate was $40.3 \%$ in rainy season and $65.9 \%$ in dry season. The TP removal rate was $43.0 \%$ in rainy season and $43.2 \%$ in dry season. The removal rates of TP and TN in dry season are higher than in rainy season. The removal efficiency of TN is higher than TP. The removal rates of SS in the overlying water $47.58 \%$ in rainy season and $49.88 \%$ in dry season.

Distribution of nutrients in sediments of ecological restoration area was obviously different. The $\mathrm{OM}$ was $38.64 \mathrm{~g} / \mathrm{kg}$ in dry season and $34.58 \mathrm{~g} / \mathrm{kg}$ in rainy season. Moreover, it was $33.19 \mathrm{~g} / \mathrm{kg}$ in downstream and $39.48 \mathrm{~g} / \mathrm{kg}$ in upstream. But the TN in sediment was $2.53 \mathrm{~g} / \mathrm{kg}$ in rainy season and $1.92 \mathrm{~g} / \mathrm{kg}$ in dry season. It was $0.21 \mathrm{~g} / \mathrm{kg}$ higher in upstream than that in downstream. The TP was $1.61 \mathrm{~g} / \mathrm{kg}$ in rainy season and $1.38 \mathrm{~g} / \mathrm{kg}$ in dry season. It was $0.22 \mathrm{~g} / \mathrm{kg}$ higher in upstream than that in downstream.

\section{Correlation analysis of nitrogen, phosphorus and organic matter in sediment and overlying water}

The correlation coefficient matrix of TN and TP in sediment-overlying water of $T$. 'zhongshanshan' ecoregion in rainy and dry season in Laoyuhe River was shown in Table 3. The correlation coefficient between TP and TN in sediment was 0.943 in rainy season and 0.757 in dry season $(P<0.01)$. There was a significant positive correlation between $\mathrm{TN}$ and $\mathrm{OM}$ in overlying water in rainy season $(P<0.05)$ with a correlation coefficient of 0.808 . There was a significant positive correlation between TN and TP in water and TP in sediment in dry season $(P<0.05)$ with a correlation coefficient of 0.540 and 0.662 . In dry season, TP and OM in sediments were positively correlated with TN and TP in overlying water $(P<0.05)$.

Table 3. Correlation analysis of surface sediment-water nitrogen, phosphorus and organic matter in dry and rainy seasons of Laoyuhe river wetland

\begin{tabular}{c|c|c|c|c|c}
\hline Rainy season & Sediment TN & Sediment TP & Sediment OM & Overlying water TN & Overlying water TP \\
\hline Sediment TN & 1 & $0.943^{* *}$ & 0.360 & 0.465 & $0.594^{*}$ \\
\hline Sediment TP & & 1 & 0.364 & $0.540^{*}$ & $0.662^{*}$ \\
\hline Sediment OM & & & 1 & $0.808^{*}$ & 0.511 \\
\hline $\begin{array}{c}\text { Overlying } \\
\text { water TN }\end{array}$ & & & & 1 & $0.879^{* *}$ \\
\hline $\begin{array}{c}\text { Overlying } \\
\text { water TP }\end{array}$ & & & & & 1 \\
\hline $\begin{array}{c}\text { Dry season } \\
\text { Sediment TN }\end{array}$ & Sediment TN & Sediment TP & Sediment OM & Overlying water TN & Overlying water TP \\
\hline Sediment TP & 1 & 0.287 & 0.020 & -0.116 & -0.202 \\
\hline \begin{tabular}{c} 
Sediment OM \\
\hline $\begin{array}{c}\text { Overlying } \\
\text { water TN }\end{array}$
\end{tabular} & 1 & $0.757^{* *}$ & $0.668^{* *}$ & $0.687^{* *}$ \\
\hline $\begin{array}{c}\text { Overlying } \\
\text { water TP }\end{array}$ & & 1 & $0.848^{* *}$ & $0.816^{* *}$ \\
\hline
\end{tabular}

**Significant correlation at 0.01 *Significant correlation at 0.05 
Assessment pollution risk of the ecological restoration area of the $T$. 'zhongshanshan'

This paper used the comprehensive pollution index evaluation method and organic index evaluation method to evaluate the pollution status of surface sediments in the $T$. 'zhongshanshan' wetland of Dianchi Lake. It based on the distribution characteristics of TN, TP and OM in the surface sediments. The results were shown in the Table 4. The results showed that the comprehensive pollution index which all of them belong to severe pollution is as follows: upstream $>$ midstream $>$ downstream (rainy season); downstream $>$ upstream $>$ midstream (dry season).

Table 4. Comprehensive assessment pollution risk of surface sediments in dry and rainy seasons of assessment pollution risk

\begin{tabular}{c|c|c|c|c|c|c|c}
\hline \multirow{4}{*}{ Rainy season } & Area & STP & Grade & STN & Grade & FF & Level \\
\cline { 2 - 8 } & Upstream & 2.96 & 4 & 5.00 & 4 & 4.52 & Heavy \\
& Midstream & 2.56 & 4 & 4.40 & 4 & 3.97 & Heavy \\
& Downstream & 2.51 & 4 & 4.38 & 4 & 3.94 & Heavy \\
\hline \multirow{5}{*}{ Dry season } & Area & STP & Grade & STN & Grade & FF & Level \\
\cline { 2 - 8 } & Upstream & 2.45 & 4 & 3.47 & 4 & 3.23 & Heavy \\
& Midstream & 2.26 & 4 & 3.40 & 4 & 3.13 & Heavy \\
& Downstream & 2.18 & 4 & 3.62 & 4 & 3.28 & Heavy \\
\hline
\end{tabular}

Applying the organic pollution index to evaluate the organic pollution of surface sediments of $T$. 'zhongshanshan' ecoregion is shown in Table 5. The distribution of organic pollution in the rainy or dry seasons of $T$. 'zhongshanshan' ecoregion along the lakeside is as follows: upstream $>$ midstream $>$ downstream. The organic pollution was moderate except water inlet in rainy season that was level III (heavily polluted).

Table 5. Assessment of organic pollution in surface sediments of Laoyuhe river wetland in dry and rainy seasons

\begin{tabular}{c|c|c|c|c|c}
\hline \multirow{4}{*}{ Rainy season } & Area & OC/\% & ON/\% & OI/\% & Level \\
\cline { 2 - 6 } & Upstream & 2.06 & 0.26 & 0.54 & IV \\
& Midstream & 2.13 & 0.23 & 0.49 & III \\
& Downstream & 1.83 & 0.23 & 0.42 & III \\
\hline \multirow{5}{*}{ Dry season } & Area & $\mathbf{O C} / \%$ & ON/\% & OI/\% & Level \\
\cline { 2 - 6 } & Upstream & 2.52 & 0.18 & 0.46 & III \\
& Midstream & 2.18 & 0.18 & 0.39 & III \\
& Downstream & 2.02 & 0.19 & 0.38 & III \\
\hline
\end{tabular}

\section{Discussion}

Spatial distribution characteristics of nutrients elements in the ecological restoration area of the T. 'zhongshanshan' in Dianchi Lakeside wetland

(1) There are differences in nutrient elements in overlying water between rainy season and dry season. Compare with dry season, the average content of TN in rainy season was $2.3 \mathrm{mg} / \mathrm{L}$ higher than in dry season, while TP in rainy season was $0.12 \mathrm{mg} / \mathrm{L}$ 
also higher than in dry season. Dianchi Lake Basin is a phosphorus-rich area, the lakeside wetland of the Laoyuhe River is located in the East Bank of the Dianchi Lake (Zeng et al., 2017) where agricultural non-point sources have become the main pollution sources.

According to research, crops such as flowers and vegetables in dry season are widely planted which were the main causes of agricultural non-point source pollution in the basin. These crops require large amounts of fertilizer and have high nutrient surpluses (Zeng et al., 2017). Therefore, the loss and migration of phosphorus have become an important source of water pollution in the phosphorus-rich area, Dianchi Lake, with the increase of precipitation in rainy season. The nitrogenous and phosphorus fertilizer in the soil with the heavy rain washed into the river channel and finally entered the $T$. 'zhongshanshan' wetland. Then, it makes the content of nutrients in the overlying water in rainy season are much higher than those in dry season.

(2) In T. 'zhongshanshan' wetland, the removal rate of TN and TP in overlying water in dry season is higher than that in rainy season. The removal rate of TN was $25.6 \%$ higher in dry season than in rainy season. The removal rate of TP in dry season was $0.2 \%$ higher than in rainy season. The first reason is that the content of TN, TP and other nutrients in the overlying water is higher in rainy season than those in dry season. Secondly, the higher hydraulic load and longer hydraulic residence time can makes higher removal efficiency. There are an amount of water, fast flow rate and short hydraulic retention time in $T$. 'zhongshanshan' ecoregion in rainy season. That is consistent with that the purification effect of T. 'zhongshanshan' on mild and moderate eutrophic wastewater was better than heavy (Hua et al., 2013; Han et al., 2015). Meanwhile, that the growth of $T$. 'zhongshanshan' is stable in the dry season causes the unique climatic conditions of Kunming (Ma et al., 2011). So the nutrient elements removal rate such as $\mathrm{TN}$ and $\mathrm{TP}$ are kept at a certain rate to promote $\mathrm{TN}$ and $\mathrm{TP}$ reduction in dry season.

(3) The content of TP in sediment is higher in rainy season than in dry season. Also it is higher in upstream than downstream in research area. The spatial and temporal distribution of nutrient elements such as TN, TP and OM in sediments are mainly affected by many reasons such as exogenous inputs, sedimentary environment, human factors, hydrodynamic conditions and pollution conditions (Marton et al., 2014). The content of TP in the sediment in rainy season is higher than that in dry season because of a large amount of phosphorus entered the T. 'zhongshanshan' wetland with soil erosion in rainy season especially Dianchi Lake which is located a phosphorus-rich area (Ma et al., 2015). The particulate phosphorus in the soil is intercepted and settled into the sediment by the roots of $T$. 'zhongshanshan' and other plants. The absorption of phosphorus nutrients in the roots of plants plays a certain role in reducing the pollution of total phosphorus in sediments. Therefore, the content of TP in the sediment in upstream of T. 'zhongshanshan' ecological restoration area was higher than that in the downstream which is consistent with Varol's (2013) and Dzakpasu et al.'s (2015) studies.

(4) The effect of $T$. 'zhongshanshan' on the TN removal efficiency in overlying water and sediment are not consistent which mainly due to the different morphology of $\mathrm{N}$ in water-sediment system (Hossain et al., 2016). The TN in overlying water was $3.98 \mathrm{mg} / \mathrm{L}$ with the removal efficiency of $41.65 \%$, while the $\mathrm{TN}$ in sediment was $1.99 \mathrm{~g} / \mathrm{kg}$ with the removal efficiency of $27.29 \%$. The average content of TN in surface sediment of $T$. 'zhongshanshan' wetland was higher than many other lakeside wetlands. 
such as Taihu Lake, Chaohu Lake, Hongze Lake, the nitrogen substances also was mainly absorbed from the overlying water in the growth process of $T$. 'zhongshanshan' which played indispensable role (Stottmeister et al., 2003). Furthermore, nitrogen is released and returned to the sediment because the dense $T$. 'zhongshanshan' restoration area produced a large amount of litters which degrade. It increased the content of TN in the sediment (Jacobson et al., 2014).

Based on the monitoring results of TP, TN, OM at the 27 sampling sites, the spatial distribution of average TP, TN, OM in the surface sediment of $T$. 'zhongshanshan' wetland is shown in Figure $4 a, b$.
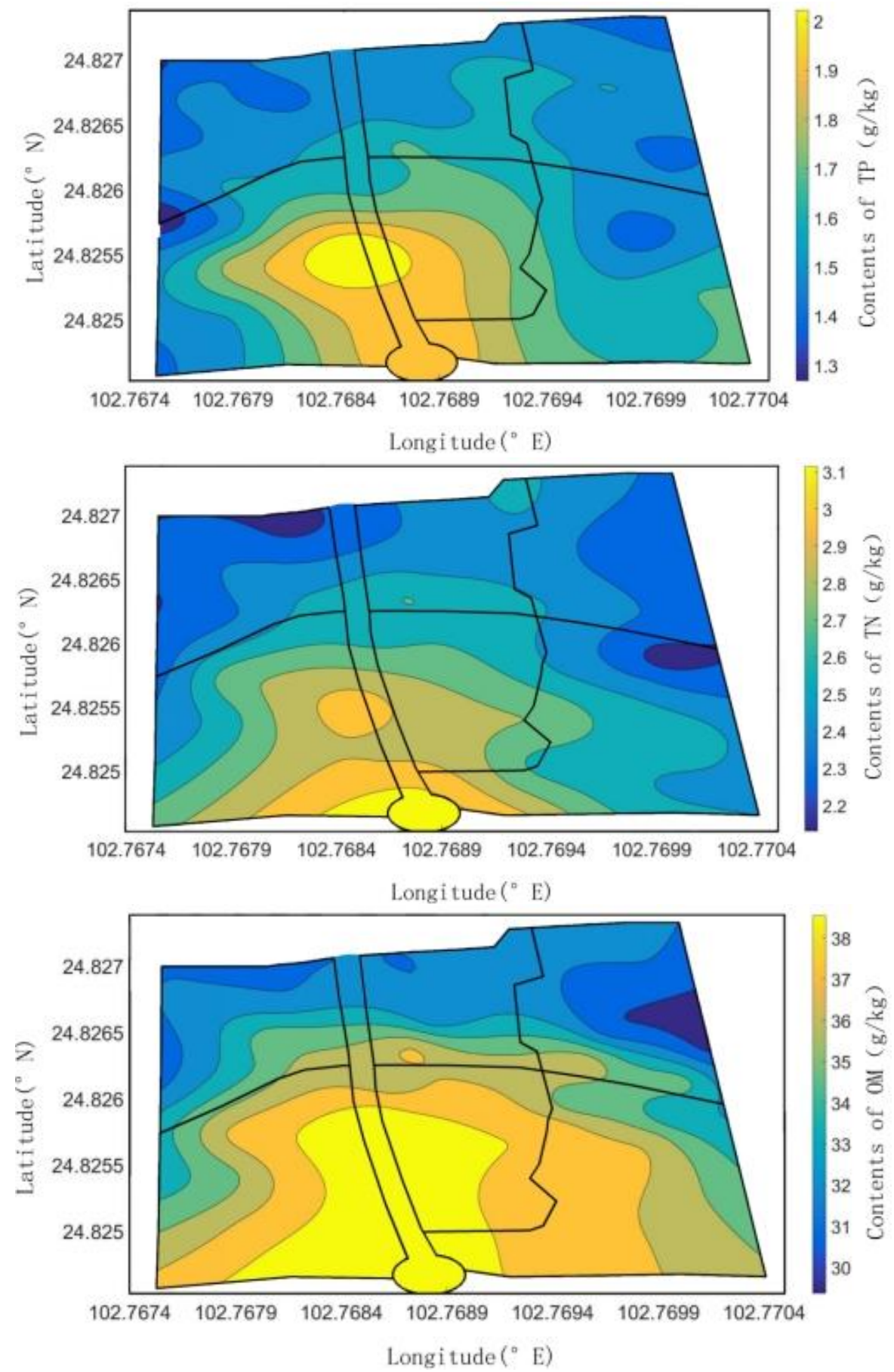

(a) 

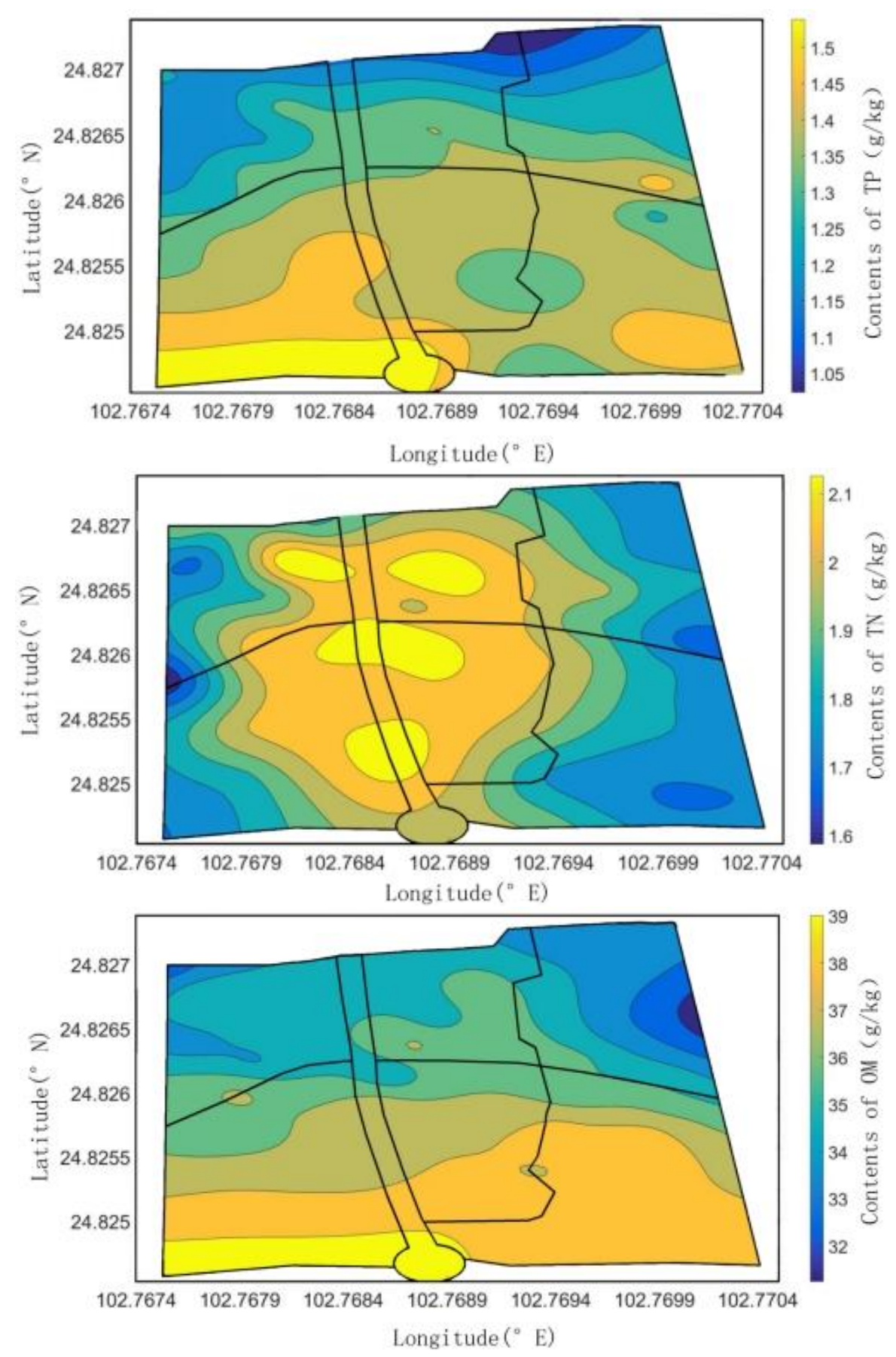

(b)

Figure 4. The spatial distribution of average TP, TN, OM in the surface sediment of research area in rainy season (a) and in dry season (b). Abscissa axis is Longitude, ordinate axis is Latitude, black lines in colourful area (our research area) are the boundary of different units $T$. 'zhongshanshan' forests in Laoyuhe River wetland

\section{Correlation of nutrient elements in Sediment- Overlying water}

According to correlation analysis, the TP in sediments was a significant positive correlation with TN in sediments $(\mathrm{P}<0.01)$, but no correlation with $\mathrm{OM}$ in rainy season. The TP in sediments was positively correlated with $\mathrm{OM}(\mathrm{P}<0.01)$ but not with the TN in 
sediments in dry season. It indicated that there are differences in the sources of nitrogen and phosphorus pollution in the sediments of the Laoyuhe River wetland in the different seasons. Compared with the research of Sediments in Tigris river basin, lake mouth wetland of Erhai Lake and Taihu Lake basin (Yang et al., 2014; Wang et al., 2016; Ouyang et al., 2018 ) the reduction of $\mathrm{N}$ and $\mathrm{P}$ in the rainy season is significantly correlated, while the $\mathrm{OM}$ in the dry season was a significant source of TP in sediments. The TN and TP mainly affect by exogenous factors while OM affect by endogenous factors. Also, the source of pollution is mainly exogenous in rainy season and endogenous in dry season.

In addition, the OM play an important role on the release of nitrogen and phosphorus. For example, Wang et al. (2011) and Di Luca et al. (2017) found that the larger variation range of nitrogen and phosphorus release in sediments when it under heavy organic pollution. So it can be inferred that the potential release risk of nitrogen and phosphorus from surface sediments of $T$. 'zhongshanshan' wetland around Dianchi Lake during rainy season is higher. It was more likely to cause secondary pollution to overlying water.

\section{Pollution assessment of T. 'zhongshanshan' ecoregion on the lakeside of Dianchi Lake}

Currently, there is no report on the methods and standards for evaluated the pollution status in shallow lake sediments. The research is mainly focused on the Organic Index (OI) and Organic Nitrogen $(\mathrm{ON})$ evaluation methods which that only considered the $\mathrm{OM}$ and ON, but ignored the presence of phosphorus (Qiu et al., 2016). Some researchers adopted the method developed by Ontario Department of Environment and Energy in Canada since 1992, for the environmental quality assessment standard ( $\mathrm{Li}$ et al., 2016). Although the method has derived from the ecological toxicity analysis of marine sediments, it takes the phosphorus into account.

The comprehensive and organic pollution levels were between moderate and severe levels in the sediments of T. 'zhongshanshan' wetland which has consistent results on the FF and OI. The pollution level of surface sediment of $T$. 'zhongshanshan' wetland around Dianchi Lake is at a high level which showed a difference with the plain wetland such as Sundarbans mangrove forest wetlands, Hongkong coastal wetland and Min River Estuary Wetland's evaluation results of sediment pollution (Mustafa et al., 2011; Hossain et al., 2016; Hu et al., 2014).

Sediment is a reservoir of nitrogen and phosphorus nutrients in wetlands (Zhang et al., 2013). The release of nitrogen and phosphorus from sediments will gradually become the focus of eutrophication control of water after the control of exogenous sources. Although not all forms of nitrogen and phosphorus can be released into water, the TN and TP forms of sediments represent the pollution degree and potential release risk of nitrogen and phosphorus in sediments (Wang et al., 2012).

The FF and OI indices of sediments from T. 'zhongshanshan' wetland in the lakeside of Dianchi were higher in rainy season than in dry season.

It is easy to cause sediment of $T$. 'zhongshanshan' wetland disturbance and resuspension under the action of hydraulic force when an amount of increased water enter in rainy season. It is helpful for the release or regeneration of nutrients.

\section{Conclusion}

This study quantitatively assessed the spatial distribution of nutrient levels as indicated by TP, OM, TN and SS in sediment and overlying water of $T$. 'zhongshanshan' wetland of Dianchi Lakeside to lay the groundwork for further 
sedimentary remediation and pollution prevention. The contents of nutrients were higher in water inlet than in water outlet. The removal rates of TN and TP in water are higher in upstream than in downstream. Meanwhile, the reduction of $\mathrm{TN}$ was significantly different in water and sediments. TP and $\mathrm{TN}$ in the rainy season were significantly higher than in the dry season. TN were mainly from agricultural non-point source pollution. TP were mainly from rich phosphorus around Dianchi ((Zeng et al., 2017); Ma et al., 2015). They washed into wetlands as exogenous pollutes in rainy season, then they settled and released into wetlands as endogenous pollutes in the dry season. The nitrogen and phosphorus pollution of sediments were all severe pollution both in dry and rainy season of $T$. 'zhongshanshan' ecoregion, but the organic pollution was basically moderate.

The T. 'zhongshanshan' lakeside wetland is the first ecological restoration area around Dianchi. Non-point resource pollutants are rapidly and efficiently absorbed, degraded and converted. Although the reduction effect of this single plant is efficient, there is still a part of the pollutants flowing into the next ecological restoration area along with surface runoff. Therefore, other wetland plants such as Typha orientalis presl and Phragmites communis in the downstream restoration areas should be mainly constructed. These repair strategies should form a complementary function and strengthen the interception of pollutants in the lakeside wetland of Dianchi Lake.

Acknowledgments. We thank reviewers from Kunming Dianchi Lake Pollution Prevention and Control Cooperative Research Center, China. This study was financial supported by Yunnan Provincial Fund project (2019J0573).

\section{REFERENCES}

[1] Di Luca, G. A., Maine, M. A., Mufarrege, M. M., Hadad, H. R., Pedro, M. C., Sánchez, G. C., Caffaratti, S. E. (2017): Phosphorus distribution pattern in sediments of natural and constructed wetlands. - Ecological Engineering 108: 227-233. DOI: 10.1016/j.ecoleng.2017.08.038.

[2] Dzakpasu, M., Wang, X., Zheng, Y., Ge, Y., Xiong, J., Zhao, Y. (2015): Characteristics of nitrogen and phosphorus removal by a surface-flow constructed wetland for polluted river water treatment. - Water Science and Technology 71(6): 904-912. DOI: 10.2166/wst.2015.049.

[3] Fulton, R. S., Godwin, W. F., Schaus, M. H. (2015): Water quality changes following nutrient loading reduction and biomanipulation in a large shallow subtropical lake, Lake Griffin, Florida, USA. - Hydrobiologia 753(1): 243-263. DOI: 10.1007/s10750-015-2210-8.

[4] Han, L. W., Hua, J. F., Yin, Y. L., Yu, C. G., Shi, Q. (2015): Purification of eutrophic water by four Chinese cedar varieties. - Chinese Journal of Environmental Engineering. 9 3311-3318.

[5] Hossain, G. M., Bhuiyan, M. A. H. (2015): Spatial and temporal variations of organic matter contents and potential sediment nutrient index in the Sundarbans mangrove forest, Bangladesh. - KSCE Journal of Civil Engineering 20(1): 163-174. DOI: 10.1007/s12205-015-0333-0.

[6] Hu, M. J., Zou, F. F., Tong, C., Hu, W. F., Ji, Q. Y. (2014): Contents and ecological risk assessment of biogenic elements in estuary wetland sediments of Min River. - Journal of Soil \& Water Conservation. 28(3) 121-126.

[7] Hua, J. F., Yin, Y. L. (2013): Application potential of T. zhongshanshan in wetland construction. Botany in ecological civilization construction: present and future. The 15th Annual Congress of the Chinese Botanical Society and the 80th Anniversary Academic Year Will.

[8] Jacobson, T. K. B., Bustamante, M. M. C. (2014): Leaf Litter Decomposition and Nutrient Release Under Nitrogen, Phosphorus and Nitrogen Plus Phosphorus Additions in 
a Savanna in Central Brazil. - Sutton, M. A. et al. (eds.) Nitrogen Deposition, Critical Loads and Biodiversity. Springer, Dordrecht, pp. 155-163. DOI: 10.1007/978-94-0077939-6_17.

[9] Kapelewska, J., Kotowska, U., Karpińska, J., Astel, A., Zieliński, P., Suchta, J., Algrzym, K. (2018): Water pollution indicators and chemometric expertise for the assessment of the impact of municipal solid waste landfills on groundwater located in their area. Chemical Engineering Journal. DOI: 10.1016/j.cej.2018.11.137.

[10] Li, J. L., Zheng, B. H., Zhang, L. S., Jin, X. W., Hu, X. P., Liu, F., Shao, J. (2016): Characteristics and differences of eutrophication in the main estuary of China. - China Environmental Science 36(2) 506-516.

[11] Li, L. P., Liu, L., Wang, S. R., Liu, W. B., Jiao, L. X., Yang, Y., Yang, R. (2015):Spatial distribution of phosphorus fractions in sediment and the potential mobility of phosphorus in Dianchi Lake. - Environ Earth Sci. DOI: 10.1007/s12665-015-4151-y.

[12] Zeng, X. L., Wang, T.T., Luo, W. S., Liu, D., Ding, W. C., Wang, S. S. (2017): Characteristics and simulation of rainfall runoff and nitrogen $\&$ phosphorus outputs in facil-ity agricultural area: A case study of flower greenhouse region in the East Coast of Lake Dianchi - J.Lake Sci. 29( 5) : 1061-1069. DOI 10. 18307 / 2017. 0504.

[13] Ma, G., Wang, S. (2015): Temporal and spatial distribution changing characteristics of exogenous pollution load into Dianchi Lake, Southwest of China. - Environmental Earth Sciences 74(5): 3781-3793. DOI: 10.1007/s12665-015-4721-z.

[14] Ma, M. J., Yang, W., Li, B. (2007): Measures and effects of ecological restoration engineering in the lakeside of Yuyu River. - Environmental Science Guide 26 26-28.

[15] Marton, J. M., Roberts, B. J. (2014): Spatial variability of phosphorus sorption dynamics in Louisiana salt marshes. - Journal of Geophysical Research: Biogeosciences 119(3): 451-465. DOI: 10.1002/2013jg002486.

[16] Mayo, A. W., Muraza, M., Norbert, J. (2018): Modelling nitrogen transformation and removal in Mara River basin wetlands upstream of Lake Victoria. - Physics and Chemistry of the Earth, Parts A/B/C 105: 136-146. DOI: 10.1016/j.pce.2018.03.005.

[17] Mustafa, A., Scholz, M. (2011): Nutrient accumulation in Typha latifolia Land sediment of a representative integrated constructed wetland. - Water, Air, \&Soil Pollution 219 329-341.

[18] Naranjo, R. C., Niswonger, R. G., Smith, D., Rosenberry, D., Chandra, S. (2018): Linkages between hydrology and seasonal variations of nutrients and periphyton in a large oligotrophic subalpine lake. - Journal of Hydrology. DOI: 10.1016/j.jhydrol.2018.11.033.

[19] Oldenborg, K. A., Steinman, A. D. (2019): Impact of sediment dredging on sediment phosphorus flux in a restored riparian wetland. - Science of the Total Environment 650: 1969-1979. DOI: 10.1016/j.scitotenv.2018.09.298.

[20] Ouyang, W., Yang, W., Tysklind, M., Xu, Y., Lin, C., Gao, X., Hao, Z. (2018): Using river sediments to analyze the driving force difference for non-point source pollution dynamics between two scales of watersheds. - Water Research 139: 311-320. DOI: 10.1016/j.watres.2018.04.020.

[21] Pan, K., Wang, W. X. (2012): Trace metal contamination in estuarine and coastal environments in China. - Science of the Total Environment 421-422 3-16.

[22] Qiu, Z. K., Hu, X. Z., Yao, C., Zhang, W. H., Xu, Q. J., Huang, T. Y. (2016): Pollution characteristics and evaluation of nitrogen, phosphorus and organic matter in sediments of Shanmei Reservoir in Fujian, China. - Environmental Science 37(4) 1389-1396.

[23] Reeves, R. R., Wilke, M., Cashmore, P., Macdonald, N., Thompson, K. (2018): Physical and ecological effects of rehabilitating the geothermally influenced Waikite Wetland, New Zealand. - Journal of Environmental Management 228: 279-291. DOI: 10.1016/j.jenvman.2018.09.027.

[24] Stottmeister, U., Wießner, A., Kuschk, P., Kappelmeyer, U., Kästner, M., Bederski, O., Moormann, H. (2003): Effects of plants and microorganisms in constructed wetlands for 
wastewater treatment. - Biotechnology Advances 22(1-2): 93-117. DOI: 10.1016/j.biotechadv.2003.08.010.

[25] Varol, M. (2013): Temporal and spatial dynamics of nitrogen and phosphorus in surface water and sediments of a transboundary river located in the semi-arid region of Turkey. Catena 100: 1-9. DOI: 10.1016/j.catena.2012.08.003.

[26] Wang, L. Z., Wang, G. X., Yu, Z. F., Zhou, B. B., Ge, X. G. (2011): Study on simulation of phosphorus release from lake sediments caused by wind and waves disturbance. Journal of Soil and Water Conservation 25(2): 121-124, 129.

[27] Wang, S., Jiao, L. X., Yang, S., Jin, X., Yi, W. (2012): Effects of organic matter and submerged macrophytes on variations of alkaline phosphatase activity and phosphorus fractions in lake sediment. - Journal of Environmental Management 113: 355-360. DOI: 10.1016/j.jenvman.2012.09.007.

[28] Wang, S. J., Liu, Y. G., Wang, Y., Hou, L., Zhang, C. (2016): Vertical distribution and pollution risk assessment of nitrogen, phosphorus, and organic matter in sediment of inflowing rivers of Erhai Lake estuarine wetland in wet and dry seasons. - Environmental Science 12 4615-4625.

[29] Weyer, C., Peiffer, S., Lischeid, G. (2018): Stream water quality affected by interacting hydrological and biogeochemical processes in a riparian wetland. - Journal of Hydrology 563: 260-272. DOI: 10.1016/j.jhydrol.2018.05.067.

[30] Wondie, A. (2018): Ecological conditions and ecosystem services of wetlands in the Lake Tana Area, Ethiopia. - Ecohydrology \& Hydrobiology 18(2): 231-244. DOI: 10.1016/j.ecohyd.2018.02.002.

[31] Xue, W., Lu, S. Y. (2015): Effects of inactivation agents and temperature on phosphorus release from sediment in Dianchi Lake. - Environ Earth Sci, China. DOI: 10.1007/s12665-014-3910-5.

[32] Yang, Y., Liu, Q. G., Hu, Z. J., Zhang, Y. M., Gao, Y. X. (2014): Spatial distribution of sediment carbon, nitrogen and phosphorus and pollution evaluation of sediment in Taihu Lake Basin. - Acta Scientiae Circumstantiae 34: 3057-3064.

[33] Yang, Y., Gao, B., Hao, H., Zhou, H. D., Lu, J. (2017): Nitrogen and phosphorus in sediments in China: a national-scale assessment and review. - Science of the Total Environment 576 840-849.

[34] Zhang, B., Fang, F., Guo, J., Chen, Y., Li, Z., Guo, S. (2012): Phosphorus fractions and phosphate sorption-release characteristics relevant to the soil composition of water-levelfluctuating zone of Three Gorges Reservoir. - Ecological Engineering 40: 153-159. DOI: 10.1016/j.ecoleng.2011.12.024.

[35] Zhang, Z. M., Lin, S. X., Zhang, Q. H., Guo, Y., Lin, C. H. (2013): Distribution characteristics of soil carbon, nitrogen and phosphorus in Caohai Plateau wetland under different land use patterns. - Journal of Soil and Water Conservation 27(6) 199-204.

[36] Zhang, Z., Lv, Y., Zhang, W., Zhang, Y., Sun, C., Marhaba, T. (2014): Phosphorus, organic matter and nitrogen distribution characteristics of the surface sediments in Nansi Lake, China. - Environmental Earth Sciences 73(9): 5669-5675. DOI: 10.1007/s12665014-3821-5.

[37] Zhu, Y., Jin, X., Tang, W., Meng, X., Shan, B. (2018): Comprehensive analysis of nitrogen distributions and ammonia nitrogen release fluxes in the sediments of Baiyangdian Lake, China. - Journal of Environmental Sciences DOI: 10.1016/j.jes.2018.05.024. 